\title{
Tentativas e perspectiva de formação de uma burocracia pública no Brasil
}

\section{Introdução}

A organização da burocracia na Administração Pública brasileira é preocupação que já completou mais de 50 anos. De uma forma geral, a história administrativa do País é caracterizada por uma alternância pendular de decisões sobre a mittéria. De fato, em raros periodos tem-se, de maneira inequivoca, a presença de elementos que atendam aos pré-requisitos da constituição de uma burocracia orgânica que garanta a qualidade e a continuidade das ações governamentais. Para tal, algumas exigências se colocam. Inicial e principalmente, é preciso que as formas de admissão ao serviço público tenham como pressuposto mecanismos que assegurem a presença de critérios institucionais e objetivos de aferição do mérito e de igualdade de oportunidade. Trata-se de requisitos não apenas de um serviço público eficiente, mas, também, da própria democracia.

\section{A tentativa daspiana e a redemocratização}

As primeiras tentativas sistemáticas de instituição de uma burocracia orgânica seguem-se à Revolução de 1930 , em um período em que o Governo, fruto do esgotamento do modelo de Estado existente até então, percebe a necessidade de sua constituição, para o exercício do poder público de forma eficiente. Trata-se de exigência do próprio crescimento da complexidade da ação estatal. Vale registrar que os anos 30 são marcados pelo fato de o Governo passar a atuar em novas áreas. É sintomática a criação dos Ministérios da Educação e Saúde Pública e do Trabalho, Indústria e Comércio. A atividade de elaboração e implementação de politicas públicas começa a exigir maior especialização e profissionalismo.

Gilberto

Guerzoni Filho é Assessor Legislativo do Senado Federal 
Isto se reflete na Carta Constitucional de 1934, que é a primeira a trazer um título específico para os funcionários públicos.

Dentro do processo de modernização do Estado, o Governo Federal fez aprovar a Lei no 284, de 1936, que iniciou a sistematização do Serviço Público Federal, adotou os critérios então conhecidos para organização de pessoal, deu início ao processo de classsificação de cargos, separando os cargos efetivos dos em comissão, excluindo estes das carreiras, organizou uma grade de remuneração dos cargos públicos e criou o Conselho Federal do Serviço Público Civil, primeiro órgão voltado especificamente para a gestão da função administrativa no Brasil.

Em 1938, o Conselho Federal do Serviço Público Civil dá origem ao Departamento Administrativo do Serviço Público - DASP - que avançou no sentido de uma sistematização das normas sobre o pessoal civil, consolidando-se o instituto do concurso público e o da estabilidade e estabelecendo, no Serviço Público Federal, normas modernas de gestão da coisa pública.

O processo de redemocratização, que se iniciou a partir da queda do Estado Novo, trouxe consigo um desvirtuamento dos trabalhos até então desenvolvidos pelo DASP. Sob pressão do funcionalismo, a Constituição de 1946, no Art. 23 do seu Ato das Disposições Constitucionais Transitórias, efetivou os funcionários interinos e extranumerários, admitidos sem concurso público.

A primeira grande tentativa de profissionalizar a Administração Pública não fora suficiente para afastar toda uma tradição de usar o serviço público como importante moeda de troca no jogo político-partidário.

Apesar disso, o funcionalismo público ganhou, em 28 de outubro de 1952, o Estatuto dos Funcionários Públicos Civis da União, com a promulgação da Lei ñ. 1.711. A norma estatutária passou a reger o trabalho no serviço público e o concurso público tornou-se a regra geral de admissão.

Estes principios foram, entretanto, sistematicamente burlados em toda uma série de diplomas legais posteriores, donde se destaca a Lei no 4.069, de 11 de junho de 1962, que representou o último grande e, talvez, definitivo golpe no sistema de mérito para acesso e desenvolvimento no Serviço Público, cuja implantação foi intentada pelo DASP, a partir de sua criação em 1938.

Esta Lei, denominada, pelo eminente jurista e Ministro do Supremo Tribunal Federal Evandro Lins e Silva, em julgado proferido sobre a matéria, de Lei de Favor, determinou o enquadramento, como servidores públicos, de todos aqueles que contassem, na data de sua publicação, com cinco anos de serviço público, independentemente da forma de admissão ou contratação, e coroou um processo que teve início com a estabilização concedida aos interinos e extranumerários pela Carta de 1946. As conse- 
qüências da Lei n: 4.069, de 1962, foram tanto mais graves na medida em que ensejaram o enquadramento, como servidores públicos, de boa parte dos contratados para trabalhar na estrutura administrativa extraordinária e paralela à máquina regular, montada pelo Governo Federal para a construção e instalação da nova Capital Federal. Todo este processo fez com que, no início da década de 1960, estivesse a Administração Federal inchada e incapaz de realizar, de forma eficiente e eficaz, as suas obrigações.

Observe-se o desabafo do Diretor-Geral do DASP, servidor zeloso, preocupado com a moralidade da gestão da coisa pública, ao verificar as situações a que a legislação de pessoal vinha obrigando a Administração a assumir, na Exposição de Motivos n'. 103, de 17 de fevereiro de 1964:

"Infere-se assim que para desembaraçar-se de servidores seus admitidos a título precário para servirem em atividades sem o ostensivo e manifesto caráter de permanência, servidores não estáveis e, portanto, sem aquelas garantias que a Constituição solenemente confere aos estáveis, a Administração deverá conformar-se à contingência de mantê-los a seu serviço porque a Legislação de Pessoal foi progressivamente fazendo tábua rasa dos princípios constitucionais e ampliando e fortalecendo de tal maneira os direitos dos funcionários a ponto de hoje não se poder distinguir o estável dos que não conquistaram tal direito".

É importante registrar a situação peculiar do governo Juscelino Kubitschek, que se elege com um ambicioso programa de atuação, o Programa de Metas, que reflete a necessidade da intensificação da ação do Estado no dominio econômico. O Governo, diagnosticando a incapacidade da máquina administrativa de implementar as políticas públicas propostas, ao mesmo tempo que não pode alterar, pelas exigências de sua base politico-parlamentar, o perfil do serviço público, profissionalizando-o e retirando dele a influência político-partidária, constrói uma estrutura administrativa paralela, para dar efetividade às suas politicas públicas. São os chamados Grupos Executivos que, apesar de seu significado, não perenizam a sua atuação sobre a máquina pública.

\section{Os governos militares e o Decreto-Lei no 200, de 1967}

A partir dos governos militares, surgidos como conseqüência do Movimento de 1964, inicia-se uma nova tentativa de modernização da Administração Pública brasileira. As exigências do desenvolvimento econômico apoiado na intensa ação do Estado colocam na ordem do dia a necessidade de uma Administração Pública capaz de formular e implementar políticas públicas altamente complexas e sofisticadas, para as quais a estrutura existente não estava preparada. 
Como cerne do diagnóstico do problema enfrentado pelo serviço público, colocava-se a necessidade de tornar a máquina administrativa mais ágil, mais próxima dos critérios existentes para a iniciativa privada, o que possibilitaria aumentar a sua eficiência e eficácia. Acreditava-se, na época, que um dos fatores que dificultavam o desempenho do serviço público prendia-se à pouca flexibilidade permitida pelo Estatuto aprovado pela citada Lei no. 1.711, de 1952.

Assim, a partir de 1967, facultou-se à Administração Federal admitir servidores pela Consolidação das Leis do Trabalho, ao lado daqueles estatutários. Esta duplicidade de regimes teve origem na Constituição de 24 de janeiro de 1967, que previa, em seu Art. 104, esta possibilidade.

A matéria foi regulamentada pelos Arts. 96 e 97 do Decreto-Lei no. 200, de 25 de fevereiro de 1967, que, no campo da Administração Pública, sistematizou as diretrizes de Governo e que representa, ainda hoje, um dos mais completos e articulados diplomas legais existentes, no Brasil, sobre a matéria.

Além disso, o Decreto-Lei no. 200, de 1967, também dentro da idéia de aproximar a Administração Pública dos principios que norteavam a organização da iniciativa privada, consolidou a presença, na máquina pública, das fundações criadas e mantidas pelo Poder Público (já utilizadas em grande escala pelo Presidente Juscelino Kubitschek na organização de Brasília), definidas como entidades de direito privado e, como tal, não sujeitas às normas da administração direta e autárquica relativas à admissão de pessoal. Efetivamente, o Decreto-Lei no. 200, de 1967, carrega, ao lado de seu aspecto técnico, um forte viés autoritário, excluindo a ação do Poder Executivo de controles do Poder Legislativo e da sociedade civil.

Posteriormente, o que era exceção tornou-se regra e o que era regra, exceção, pela Emenda Constitucional no 1, de 17 de outubro de 1969, e pela Lei no. 6.185, de 11 de dezembro de 1974, que estendeu, ainda mais, o dispositivo constitucional, determinando a contratação, pela legislação trabalhista, de todos os servidores públicos, salvo os das áreas de Segurança Pública, Diplomacia, Tributação, Arrecadação e Fiscalização de Tributos Federais e Contribuições Previdenciárias, e os do Ministério Público.

A utilização do regime "celetista", celebrado como o moderno, em contraposição ao estatutário, arcaico, teve tal sucesso que, no momento da implantação do Regime Juridico Único pela Lei n. 8.112, de 11 de dezembro de 1990, dos cerca de 700.000 servidores civis ativos da União, não mais de 150.000 ainda eram regidos pela Lei n' 1.711 , de 1952 .

O que ocorreu, na prática, foi que grande parte dos servidores admitidos pelo regime "celetista" o foram sem concurso público e sem direito à estabilidade. De fato, praticamente a totalidade dos servidores admitidos pelas fundações, forma jurídica em que se constituiram grande parte das entidades criadas na época, entrou no serviço público, na melhor 
das hipóteses, por um processo seletivo simplificado, onde não esteve presente o pressuposto da impessoalidade, nem qualquer mecanismo institucional de avaliação de mérito. Estes servidores foram, muitas vezes, admitidos para prestar serviços na administração direta. De fato, algumas fundações não passavam de verdadeiras intermediárias de mão-de-obra, aproveitando-se do fato de que não precisavam admitir por concurso e tinham ampla liberdade de fixação da remuneração de seus servidores. Ainda hoje, é possível observar, nos quadros de algumas fundações, um número desproporcional de servidores cedidos à administração direta, alguns que durante longo tempo, inclusive, somente tinham comparecido à sua entidade de origem, quando muito, para assinar o contrato de trabalho. Este processo ocorreu, igualmente, na administração direta e nas autarquias, com as chamadas tabelas especiais.

Impõe-se, aqui, observar que diversas empresas públicas e sociedades de economia mista, também criadas ou ampliadas em profusão durante a década de 1970, foram utilizadas como intermediadoras de mãode-obra para a administração direta, à semelhança das fundações. Algumas chegaram e ainda chegam a possuir mais da metade de seus empregados prestando serviços à administração direta, além de ser comum a existência de falsas empresas, que somente adotaram esta personalidade juridica para fugir de controle, uma vez que não exercem atividades com qualquer caracteristica empresarial.

Também dentro do processo de modernização, foi promulgada a Lei no 5.645 , de 10 de dezembro de 1970, que estabelece diretrizes para a classificação de cargos do Serviço Civil da União e das autarquias federais, e dá outras providências. Este diploma legal foi, assim como o Decreto-Lei ñ. 200, de 1967, fundamental para a reorganização da Administração Pública Federal, e representou a mais completa e melhor sistematização e classificação de cargos até então feita.

Ao lado disto, entretanto, a citada Lei n. 5.645, de 1970, cria o instituto da ascensão funcional. Trata-se de instituto que existia anteriormente, sob a denominação de acesso, na Lei no. 3.780, de 1960, e que permitia ao servidor ter acesso a cargo diverso do que exercia, mediante processo seletivo interno.

$O$ instituto era permitido pela Constituição anterior, com a redação dada pela Emenda Constitucional n. 1, de 17 de outubro de 1969.

A ascensão caracteriza-se como provimento derivado. Conforme a definição de Mello, Celso Antonio Bandeira de, Curso de Direiro Administrativo, p. 150-1:

"Os provimentos derivados, como o nome indica, são aqueles que derivam, ou seja, que se relacionam com o fato do servidor ter ou haver tido algum vínculo anterior com cargo público. Nele se radica a causa do ulterior provimento. [...] 
Provimento derivado vertical é aquele em que o servidor é guindado para cargo mais elevado. Efetua-se através das formas de provimento denominadas (a) promoção [...] e (b) ascensão.

Ascensão é a elevação de cargo alocado na classe final de uma carreira prevista como complementar da anterior e na qual parte dos cargos é preenchivel por concurso público e parte reservada para serem providos pelo meio referido".

$O$ instituto da ascensão, cuja existência foi justificada pela necessidade de se dar maior coerência às carreiras, converteu-se, de fato, numa forma de burla ao princípio do concurso público. Mediante o instituto, a escolha dos ocupantes dos cargos mais elevados passou a ser, em grande medida, feita entre os próprios servidores, anulando, na prática, o direito ao livre acesso aos cargos públicos.

Observe-se, inclusive, que, no decorrer do tempo, as exigências para a realização da ascensão funcional foram se tornando cada vez menos rígidas. A situação chegou a tal ponto que o Decreto no 94.664, de 23 de julho de 1987, que regulamentou o Plano Único de Classificação e Retribuição de Cargos e Empregos - PUCRCE — das Instituições Federais de Ensino, determina que somente seria aberto concurso público para os cargos técnico-administrativos das escolas federais se houvesse vagas remanescentes de processo seletivo interno.

Em nosso entendimento, o instituto da ascensão não se justifica, uma vez que se o servidor é competente para ter acesso ao cargo mais elevado, ele lhe é dispensável; se é apenas para facilitar este acesso, em desrespeito ao principio isonômico com os demais cidadãos, ele é indefensável e representa mera garantia corporativa.

A ascensão desatende aos dois princípios que justificam a existência do concurso público, o direito de igualdade no acesso ao cargo público e a obrigação de a Administração escolher, sempre e de forma impessoal, o melhor para o desempenho de determinada função.

Além disso, a ascensão gera um problema de desestimulo no desempenho das funções de nivel mais elementar, que perdem o seu significado, transformadas em meros canais de acesso àquelas mais complexas.

Registre-se que a ascensão não representou grande problema na época, uma vez que, como regra, o concurso público não era a forma de acesso aos cargos estratégicos de alta direção, aos quais se chegava por critérios de escolha e cooptação, conforme referido anteriormente.

A tentativa modernizadora intentada a partir do Decreto-Lei $\mathrm{n}$. 200, de 1967, e dentro da qual se insere a Lei no. 5.645, de 1970, cujos méritos são inegáveis, acabou tendo como resultados o contrário do pretendido. É importante registrar que isto não ocorreu por uma distorção da implantação da reforma, mas pelos erros de seus pressupostos, demonstrados a longo prazo. 
A máquina administrativa emerge do periodo dos governos militares absolutamente desestruturada. Cresceu o número de servidores, grande parte deles contratados sem qualquer forma de controle. Não se constituiu uma burocracia orgânica; pelo contrário, constitui-se a chamada tecnocracia, no sentido de que as funções de alta direção burocrática passaram a ser ocupadas por técnicos não ligados à administração direta, não vinculados à burocracia tradicional, organizada em carreiras. Conforme SANTOS, Luiz Alberto dos:

"Oriunda do meio acadêmico, do setor privado e das empresas estatais, e de órgãos do próprio Governo, esta tecnocracia - mais por méritos e ligações políticas e ideológicas de individuos do que por uma identidade de classe - supriu a Administração Federal de quadros para a alta administração. $O$ processo de recrutamento destes quadros deu origem, em alguns casos, à formação das chamadas ilhas de excelência em determinados órgãos ou entidades, que vieram a se tornar provedores de pessoal qualificado para a alta hierarquia ministerial e para o exercicio das atividades de formulação de políticas e regulação econômica.

A forma como tal processo se desenvolveu, a partir de iniciativas isoladas ou condições políticas ou econômicas muito localizadas, não se constitui num meio institucionalizado para o recrutamento da alta administração. [...]

Apesar de, em muitos casos, a atuação de seus integrantes no âmbito da Administração ter-se processado por períodos prolongados, a tecnocracia não conformou um ethos de serviço público. No mais das vezes, a sua ação se aproxima do esperado de profissionais do setor privado atuando circunstancialmente no setor público. Comprova esta afirmação o fato de que, em muitos casos, integrantes da tecnocracia tornaram-se consultores ou empresários no setor privado, após a sua saída do serviço público, mantendo com a Administração uma relação profissional em que esta se tornou cliente dos seus serviços, ao mesmo tempo que suas experiências no setor público tornavam-se um cobiçado produto colocado à disposição do mercado. Detentores de um know-how técnico, atuavam despidos da ideologia ou da consciência do papel de árbitros e articuladores das demandas sociais, indispensável aos agentes responsáveis pela formulação e implementação de políticas públicas, o que pode ser parcialmente explicado pelas regras do jogo vigentes durante o período autoritário. Neste sentido, cumpriram o papel esperado de técnicos politicamente neutros, formados à margem de valores, num contexto em que o debate e a articulação com o Poder Legislativo e a sociedade não eram fatores essenciais à sua atuação". 
Ao mesmo tempo é destruido o remanescente da burocracia tradicional, tanto pelo dito acima quanto pelo instituto da ascensão, que contribuiu para a completa desmoralização do concurso público e de todos os sistemas institucionais de mérito para admissão e progressão na Administração Pública.

As tentativas de flexibilização levadas adiante, se bem-sucedidas no início, fracassaram justamente por não conseguirem constituir um mecanismo permanente de controle dos entes descentralizados e pela inexistência da constituição de uma burocracia orgânica.

Na verdade, a autonomia alcançada pelas fundações e pelas empresas públicas e sociedades de economia mista, admitida e suportável no periodo de crescimento econômico, atingiu níveis insuportáveis para as finanças públicas no periodo de crise de financiamento do Estado que se seguiu, na década de 1980. Começaram a ser criados mecanismos crescentes de controle sobre estas entidades, ao mesmo tempo que se diagnosticava a necessidade de se dar maior organicidade à Administração Pública.

\section{A Nova República e os antecedentes da atual carta}

A partir do processo de redemocratização, com o governo Tancredo Neves/José Sarney, ensaiou-se uma nova tentativa de modernização da Administração Pública. Neste sentido, colocou-se a discussão da necessidade de unificação dos regimes juridicos dos servidores públicos, do fortalecimento da administração direta e do restabelecimento integral do instituto da estabilidade. Inicialmente, a Secretaria de Administração Pública da Presidência da República — SEDAP —, órgão sucessor do DASP, propôs a criação de um novo regime jurídico, denominado "civilista".

Dentro dessa tentativa, e com vistas ao reforço da burocracia, insere-se a criação das carreiras de Finanças e Controle, de Orçamento e de Especialista em Políticas Públicas e Gestão Governamental, na busca da instituição de carreiras destinadas à alta administração. A criação dessas carreiras, entretanto, não cumpriu os seus objetivos.

Com relação às carreiras de Finanças e Controle e de Orçamento, o problema foi de origem. Na constituição dessas carreiras pelos DecretosLeis n $n^{\text {os }} 2.346$ e 2.347 , ambos de 23 de julho de 1987 , determinou-se, em dispositivos cuja constitucionalidade pode ser contestada, mesmo sob a égide da Constituição de 1969, que qualquer servidor que estivesse em exercicio em órgãos do sistema de controle interno e de orçamento, independentemente de seu cargo, formação, ou da atividade que estava desempenhando, passasse, de forma automática, respectivamente, à carreira de Finanças c Controle e à de Orçamento. Como não se burla, impunemen- 
te, o princípio do concurso público, tem-se a situação, hoje, de graves problemas de qualificação e de adequação do perfil dos Analistas e Técnicos de Finanças e Controle e de Orçamento. Apenas recentemente vem sendo realizada a seleção de novos servidores para a carreira através de concurso público específico. Assim, mantiveram-se na origem dessas carreiras os mesmos graves problemas que ensejaram a sua criação.

Quanto à carreira de Especialista em Políticas Públicas e Gestão Governamental, o problema foi a descontinuidade. Foi realizado apenas um concurso público, em 1988, com grande divulgação, ao qual concorreram quase 70.000 candidatos às 120 vagas oferecidas. A carreira foi criada pela Lei $n^{\circ} .7 .834$, de 6 de outubro de 1989, tendo sido empossados nos seus cargos cerca de 100 servidores.

Apesar do significado destas tentativas, que marcaram a Administração Pública, elas tiveram, pelos motivos referidos, resultados limitados e bem aquém do esperado.

\section{A Constituição de 1988}

Na Constituinte de 1987/88, caminhou-se no sentido da aprovação da unificação dos regimes juridicos dos servidores públicos, erigida em norma constitucional no Art. 39 da Lei Maior, e do fortalecimento dos controles sobre a Administração Pública.

Pela primeira vez, de forma inequivoca, o concurso público foi explicitado como única forma de acesso ao cargo e ao emprego público. Até então, a norma do concurso público sempre permitiu mecanismos que deram condições à sua burla. Na Carta de 1946, a exigência de concurso restringia-se aos cargos de carreira, liberando a nomeação para os cargos isolados. Na Carta de 1967, a exigência de concurso existia apenas para o primeiro provimento em cargo, permitindo a ascensão funcional e a livre contratação de servidores pelo regime "celetista".

A exigência de concurso público, para acesso à função pública, constante do Art. 37, II, da Constituição de 1988, vem sendo interpretada de forma estrita pelo Supremo Tribunal Federal, em todas as ações que chegam àquela Corte, tendo se tornado fundamental para a moralização da gestão da coisa pública. Todas as tentativas de burlar os dispositivos vêm sendo bloqueadas, com grande coragem, pelo Pretório Excelso. Firma-se a jurisprudência da necessidade da realização de concursos públicos específicos para o provimento dos cargos públicos. Na Ação Direta de Inconstitucionalidade - ADIn n: 231, de 1992, julgada em 5 de agosto de 1992, um marco da jurisprudência administrativa brasileira, a decisão foi vazada nos seguintes termos: 
"Ação direta de inconstitucionalidade.

Ascensão ou acesso, transferência e aproveitamento no tocante a cargos ou empregos públicos.

O critério do mérito aferivel por concurso público de provas ou de provas e títulos é, no atual sistema constitucional, ressalvados os cargos em comissão declarados em lei de livre nomeação e exoneração, indispensável para cargo ou emprego público isolado ou em carreira. Para o isolado, em qualquer hipótese; para o em carreira, para o ingresso nela, que só se fará na classe inicial e pelo concurso público de provas ou de provas e títulos, não o sendo, porém, para cargos subseqüentes que nela se escalonam até o final dela, pois, para estes, a investidura se fará pela forma de provimento que é a 'promoção'.

Estão, pois, banidas das formas de investidura admitidas pela Constituição a ascensão e a transferência, que são formas de ingresso $\mathrm{cm}$ carreira diversa daquela para a qual o servidor público ingressou por concurso e que não são, por isso mesmo, ínsitas ao sistema de provimento em carreira, ao contrário do que sucede com a promoção, sem a qual obviamente não haverá carreira mas, sim, uma sucessão ascendente de cargos isolados.

O Inciso II do Art. 37 da Constituição Federal também não permite o 'aproveitamento', uma vez que, nesse caso, há igualmente o ingresso em outra carreira sem o concurso exigido pelo mencionado dispositivo".

Mais recentemente, o Supremo Tribunal Federal concedeu liminar, no julgamento da ADIn n:. 837, de 1993, suspendendo os dispositivos da Lei no 8.112, de 11 de dezembro de 1990, que mantinham o instituto da ascensão.

Por oportuno, registre-se que, hoje em dia, não cabe nem mesmo o argumento de que uma carreira poderia ser compostá de cargos de níveis diversos e que a mudança de nivel seria objeto de promoção e não de ascensão. Tratar-se-ia, apenas, de tentar atribuir ao instituto da ascensão denominação diversa para dar-lhe roupagem de constitucionalidade. Observe-se, v.g., a decisão do STF sobre o mandado de segurança no 21420 , de 1993, impetrado por Técnicos de Finanças e Controle Externo da Carreira de Finanças e Controle Externo do Tribunal de Contas da União (cargos de nivel médio) contra decisão da Corte de Contas de realizar concurso público, e não interno, para provimento dos cargos de Analista (nivel superior), da mesma Carreira.

A própria hipótese da transformação de cargos foi excluída. Aqui, também, já se manifestou a Corte Suprema, na Ação Direta de Inconstitucionalidade n:. 266, de 1993. 
Hoje, não mais se contesta, inclusive, a exigência do concurso público para admissão de empregados pelas empresas públicas e sociedades de economia mista, entidades de direito privado integrantes da Administração Pública, que chegou a provocar grande debate. A polêmica surgiu no cotejo de dois dispositivos da Carta vigente. São eles o Art. 37, II, e o Art. 173, § $1^{\circ}$, que determina a sujeição das estatais ao regime juridico próprio das empresas privadas, no que se refere às obrigações trabalhistas e tributárias.

Vale historiar o debate sobre a questão pelo seu significado. $\mathrm{O}$ assunto é de transcendente importância por esclarecer o alcance moralizador do texto da Constituição de 1988, inesperado até por alguns ilustres analistas.

A primeira orientação geral sobre a matéria, no âmbito do Poder Executivo, nasceu do Parecer $n^{\circ}$. SA-6, de autoria do eminente ConsultorGeral da República Sebastião Baptista Affonso. O citado parecer foi aprovado pelo Presidente da República em 25 de agosto de 1989 e publicado no Diário Oficial da União de 28 subseqüente, tornando-se, daí, norma vinculante para a Administração Federal. No parecer em tela, o seu ilustre autor manifestou-se pela submissão das empresas estatais ao princípio do concurso público.

Posteriormente, o professor Clóvis Ferro Costa, sucessor de Sebastião Baptista Affonso na Consultoria-Geral da República, julgou necessário rever a questão. Emitiu, então, o Parecer n. FC-1, também aprovado pelo Presidente da República, em 31 de outubro de 1989, e publicado no D.O.U. de $1^{\circ}$. de novembro seguinte. A partir daí, o entendimento sobre a matéria, vinculante para a Administração Federal, passou a ser a dispensa do concurso para admissão nas empresas estatais.

Não é difícil entender a rápida mudança de opinião do Poder Executivo sobre a matéria, quando se perceberam os estreitos limites que o entendimento original impunha ao poder discricionário dos administradores públicos. Pela primeira vez, passava a ser impossível a utilização de subterfügios para a admissão de servidores sem concurso, contornando o texto constitucional

O Tribunal de Contas da União, que já vinha suscitando a questão desde a sessão realizada em 28 de julho de 1989, tomou decisão sobre a matéria na sessão ordinária do plenário de 16 de maio de 1990, publicada no D.O.U. de 6 de junho de i990, concluindo pela exigência do concurso público.

Após a citada decisão, a Corte de Contas vem, reiteradas vezes, determinando às empresas públicas e sociedades de economia mista, cujas contas examina, sejam tornadas nulas as contrataçôes realizadas após 6 de junho de 1990 (data da publicação da primeira manifestação do Tribunal sobre a matéria), sem prévio concurso público ${ }^{2}$ v.g. 
A questão chegou à Corte Suprema através de mandado de segurança impetrado contra a decisão do Tribunal de Contas da União. O writ recebeu o n. 021.322/92, foi relatado pelo ilustre Ministro Paulo Brossard e denegado pelo Tribunal Pleno em 3 de dezembro de 1992.

Assim, não restam dúvidas acerca da sujeição das empresas públicas e sociedades de economia mista, mesmo aquelas que exploram atividade econômica, à obrigatoriedade do concurso público para admissão de pessoal, após a edição da Constituição de 1988.

Ao lado disso, nos últimos anos, as empresas públicas e sociedades de economia mista (e, também, outras entidades e órgãos públicos), em razão do crescimento das restrições impostas sobre elas, especialmente na área de admissão de pessoal, vêm procurando promover a terceirização de grande parte de suas atividades, muitas vezes até mesmo das suas atividades-fins. Sob a égide do Enunciado no 256, a Justiça do Trabalho, nestes casos, vinha reconhecendo o vínculo desses empregados ao tomador dos serviços.

Atenta a essas questões, a Corte de Contas vem recomendando aos dirigentes das empresas vinculadas à Administração Federal que se abstenham de realizar contratação indireta de mão-de-obra para funções previstas nos respectivos planos de cargos e salários, uma vez que tal procedimento pode configurar vínculo com a empresa (v.g., Anexo XI da A ta ñ. 44, de 13 de setembro de 1989; Decisão no 203/92 - 2a. Câmara; Acórdão no. 56/93 - Plenário; Decisão no. 311/93 - Plenário).

Nos últimos tempos, entretanto, vem a Justiça do Trabalho proferindo acórdãos no sentido da impossibilidade de reconhecimento de vínculo laboral com entidades públicas sem a existência de prévio concurso público.

Recentemente, o Tribunal Superior do Trabalho, ao rever o Enunciado n. 256, emitiu o Enunciado n. 331, Diário da Justiça, 21 de dezembro de 1993, que explicita:

"A contratação irregular de trabalhador, através de empresa interposta, não gera vínculo de emprego com os órgãos da administração direta, indireta ou fundacional (Art. 37, II, da Constituição da República)".

Observa-se, do exposto, que, pela primeira vez, a lei e a jurisprudência vêm garantindo, no campo do Direito Administrativo brasileiro, o primado absoluto do concurso público especifico como forma de acesso ao serviço público efetivo.

É certo que a Constituinte foi além: a Constituição de 1988 não apenas determinou a instituição do regime jurídico único, mas erigiu o concurso público como norma fundamental e reafirmou o instituto da estabilidade aos servidores concursados. $\mathrm{O}$ texto constitucional também 
cometeu grave deslize no sentido de dificultar o caminho da Administração Pública rumo à institucionalização de uma burocracia organicamente estruturada. No Ato das Disposições Constitucionais Transitórias, em seu Art. 19, determinou a Lei Maior a estabilização de todos os servidores admitidos sem concurso que contassem com cinco anos continuados de serviço público, prevendo, ainda, a realização de concurso para fins de efetivação desses servidores.

A guisa de comentário, é importante registrar, neste ponto, que o dispositivo acima referido criou, ainda, um grave problema técnico, na medida em que concedeu estabilidade, sem a efetivação dos servidores em seus cargos. Assim, teriamos uma situação de dissociação dos dois institutos. A Lei ñ. 8.112, de 1990, que aprovou o regime juridico dos servidores civis da União, suas autarquias e fundações, passando por alto do debate que já havia em torno da questão, em seu Art. 243, determinou a efetivação de todos os servidores públicos, ocupantes de cargo efetivo ou emprego permanente na data de sua vigência, independentemente de sua forma de acesso ao serviço público ou tempo de exercício da função pública, ao total arrepio do dispositivo da Constituição, ultrapassando-o na sua já extrema generosidade.

Sobre o assunto, afirma, por exemplo, MELlo, Celso Antônio Bandeira de:

"Aliás, a sobredita lei [8.112/90] não apenas instituiu tal regime [estatutário] como geral, aplicável a quaisquer servidores públicos civis da União, mas também, [...] inconstitucionalmente, colocou sob sua égide servidores não concursados que haviam sido admitidos pela legislação trabalhista e transformou seus empregos em cargos públicos, independentemente do tempo de serviço que tivessem". 3

Ivan Barbosa Rigolin chega mesmo a se revoltar:

"O Art. 243, ponto mais baixo de qualidade técnica a que desceu o legislador nesta L. 8.112 [Lei n'. 8.112/90], simplesmente transformou, contrariando a Constituição, empregos, onde havia servidores estabilizados, em cargos estatutários". ${ }^{4}$

É importante registrar que o Supremo Tribunal Federal vem declarando a inconstitucionalidade de todas as leis estaduais e municipais que contenham dispositivos similares, veja-se, v.g., a decisão, já de mérito, tomada na Ação Direta de Inconstitucionalidade no 391, relativa ao estatuto dos servidores do Estado do Ceará. Não seria diferente, provavelmente, a decisão sobre a inconstitucionalidade do citado Art. 243 da Lei n' 8.112, de 1990, caso a matéria seja alçada àquela Corte Suprema.

Vale observar que a questão é de grande extensão, pois significa, 
por exemplo, colocar em discussão as mais de 120.000 aposentadorias estatutárias concedidas pela União aos servidores que foram objeto do citado Art. 243 da Lei no 8.1 12, de 1990.

Conforme já se referiu acima ao se tratar da Constituição de 1946, a estabilização prevista na Carta de 1988 não constitui, também, novidade em nosso Direito Constitucional. Citando FERrEIRA, Wolgran Junqueira:

"Interessante notar que a história se repete. A Constituição de 24 de janeiro de 1967, no Parágrafo $1^{\circ}$. do Artigo 97, estabelecia que a primeira investidura em cargo público dependerá de aprovação prévia, em concurso público de prova ou de prova e títulos, salvo os casos indicados em lei.

Mas, ela mesma, no parágrafo $2^{\circ}$. do $A$ rtigo 177 , dispunha: 'São estáveis os atuais servidores da União, dos Estados e dos Municípios, da administração centralizada ou autárquica, que, à data da promulgação desta Constituição, contem, pelo menos, cinco anos de serviço público'.

Cria-se, assim, um círculo vicioso. Uma Constituição proíbe o ingresso no funcionalismo, a não ser pelo concurso, a proibição não é observada e a Constituição subseqüente sacramentando a admissão feita ao arrepio da anterior.

Assim, a de 1967 sacramentou as nomeações feitas no arrepio da Constituição de 1946, a de 1988 unge as nomeações feitas contrariamente à Constituição de 1967 e, provavelmente, a revisão constitucional a ser feita em 1993, conforme dispõe o Artigo $3^{\circ}$. destas Disposições Transitórias, consagrará os que não foram contemplados por este Artigo.

E assim, sucessivamente, o país vai se tornando cada dia mais inconfiável.

O povo não acredita no governo, a falta de credibilidade gera desânimo, falta de objetivo e uma série de fatores negativos ao próprio desenvolvimento nacional, pois o povo perde a crença, a esperança e daí para frente pouco resta". 5

No mesmo sentido, desabafa Ivan Barbosa Rigolin:

"Qualquer outra forma de estabilização de servidor (que não a regra geral do corpo permanente da Constituição) há que ser tida como excepcional, como o fez no $\Lambda$ rt. 19 do ADCT - em dispositivo que sempre envergonhará o Deputado e o Senador Constituinte de 1988, verdadeira mácula injustificável, destituida do menor interesse público como se constitui, a qual premiou o mau servidor, ingresso pela porta dos fundos por proteção, apadrinhamento e motivação inconfessável, e que passou a ocupar o lugar de quem teria condições de habilitar-se em concurso". ${ }^{6}$ 
Assim, o procedimento de estabilização de servidores não concursados pode ser encontrado, também, nas Constituições de 1946 (Art. 23 do ADCT) e de 1934 (Art. 169).

As Constituições estaduais foram ainda mais longe. A do Estado do Acre determina a estabilidade do servidor que contar cinco anos de exercício na data de sua publicação, sem qualquer exceção, dando margem à estabilização de empregados de estatais e ocupantes de cargos temporários. As da Bahia, do Ceará, do Maranhão e do Rio Grande do Norte estabilizaram, explicitamente, os empregados das empresas públicas e sociedades de economia mista.

A Constituição de Santa Catarina estabilizou os servidores admitidos em caráter transitório e nem mesmo exigiu que os cinco anos de exercício para obtenção do direito fossem continuados.

No Piaui, todos os servidores admitidos até seis meses antes da promulgação da Constituição, inclusive a título de prestação de serviços, ganharam estabilidade, somente podendo ser demitidos se, submetidos a concurso público de provas e títulos, não lograssem aprovação.

Em Minas Gerais, foram estabilizados os servidores das empresas públicas e sociedades de economia mista que prestavam serviços à administração direta.

A Lei Orgânica do Distrito Federal facultou aos empregados das estatais, que optaram pelo regime "celetista" quando da transformação de seus órgãos em empresas, retornar à situação anterior.

É necessário registrar que diversos desses dispositivos foram derrubados pelo Supremo Tribunal Federal por inconstitucionalidade.

Do exposto, observa-se que, no Brasil, a questão da concessão de estabilidade do servidor público sempre extrapolou o limite do interesse público, guiando-se, muitas vezes, pelas pressões do momento. A estabilidade confundiu-se com um prêmio devido ao servidor público, exclusivamente pelo fato de ele ocupar um cargo ou emprego na Administração Pública.

Por outro lado, de fato, o instituto da estabilidade, ainda que altamente generalizado - talvez mais do que em qualquer outro pais -, não produziu na nossa Administração Pública uma efetiva continuidade. A Administração brasileira, malgrado a estabilidade no serviço público alcançada por seus servidores, padece de uma instabilidade funcional de grandes proporções. As mudanças constantes de direção nos órgãos e entidades conduzem ao que é denominado "dança de cadeiras". O quadro dirigente não se modifica no total, mas as pessoas estão, a cada momento, em um determinado órgão ou entidade. Assim, a estabilidade é inútil para assegurar continuidade e permanência. Tal situação somente pode ser corrigida com um plano de carreiras sério e com a constituição efetiva de uma burocracia. 
O que aconteceu foi a constituição de algo que poderíamos denominar de pseudoburocracia, composta pela antiga tecnocracia que, em muitos casos, foi estabilizada e efetivada em cargos pủblicos. Isto ocorreu com aqueles que foram contratados pelas fundações e pelas chamadas tabelas especiais. Com relação aos componentes da tecnocracia contratados por empresas públicas e sociedades de economia mista, que, da mesma forma que as fundações, eram utilizadas como agências de recrutamento de quadros, estes permaneceram na administração direta, formalmente requisitados de suas entidades de origem. Estes dois grupos constituem, hoje, boa parte da alta administração, e, apenas aparentemente, podem ser classificados como uma burocracia, uma vez que não têm organicidade, e, mais grave, foram alçados a elevadas funções públicas sem, quase nunca, terem sido submetidos a mecanismos institucionais de aferição de mérito. Como corolário de sua origem, esta pseudoburocracia, por não ter tido a sua vida funcional vinculada a procedimentos institucionalmente definidos, ao contrário da burocracia clássica, não guia suas ações pelos principios constitucionais da legalidade, da moralidade, da impessoalidade e da publicidade.

Outro aspecto que merece destaque é a situação em que se encontra a Administração Federal como um todo, após as sucessivas reformas por que passou nos últimos anos. Desde o final do periodo militar que a prática de promover alterações no organograma do Poder Executivo passou a ser sinônimo de reforma administrativa. Tanto as crises da Administração Pública quanto as politicas intentou-se corrigir com uma seqüência incansável de fusões, extinções e criações de ministérios e órgãos de primeiro escalão no Poder Executivo, que conduziram a uma situação de quase impossibilidade de andamento normal das atividades administrativas. Os inventários se sucedem, os servidores são deslocados permanentemente, os materiais pertencem, a cada momento, ao patrimônio de um órgão distinto, o orçamento é dividido e redividido, os dirigentes se alternam às dúzias, o próprio espaço físico ocupado pelos diversos órgãos fica permanentemente indefinido. Nestc quadro, administrar se transforma quase numa aventura sem resultados práticos.

Tudo isto conduz a uma gigantesca crise gerencial, onde não se investe na organização de carreiras de alta administração ou em capacitação dos recursos humanos existentes.

\section{Diagnóstico e alternativas para a crise}

As soluções para o equacionamento da crise por que passa a Administração Pública somente podem ser efetivas se o diagnóstico for correto. Ou corremos o risco de repetir os mesmos erros cometidos na década de 
1970, ou a experiência do governo Collor, que, segundo explica João Geraldo Piquet Carneiro ${ }^{7}$, frustrou-se por enfatizar os aspectos econômicos da reforma, limitando ao imediatismo, além de ser excessivamente abrangente, sem reunir informações para tal, tornando-se, em conseqüência, superficial. Pretendeu, ainda, a reforma ser instantânea, desprezando o investimento no processo e dando prioridade à reorganização de organogramas, em detrimento dos recursos humanos. Finalmente, o governo Collor encarou a reforma administrativa como "uma espécie de desmobilização de ativos materiais e humanos e não como investimento" $\mathrm{e}$ adotou uma estratégia autoritária e de confronto com o funcionalismo.

Vale, aqui, apenas à guisa de exemplo, lembrar que o governo Collor, apesar de todo o discurso no sentido da necessidade da redução das despesas públicas na área da Administração Pública, foi o responsável pela efetivação dos "celetistas", em conseqüência do Art. 243 da Lei no 8.112 , de 1990, certamente a grande responsável pelo grave desequilibrio nas despesas com inativos na folha de pagamento de pessoal da União. Basta observar que, apenas no periodo de um ano que se seguiu à vigência do novo estatuto, aposentaram-se, pelo Tesouro Nacional, cerca de 50 mil servidores, o triplo do que seria de esperar numa situação normal. A esmagadora maioria desses servidores, provavelmente mais de 90 por cento, vindos do Regime Geral de Previdência Social, tinha feito os seus descontos previdenciários dentro das normas daquele regime e, assim, sem qualquer contribuição para tal, ganhou aposentadoria integral, muitas vezes acrescida de incentivos e com períodos do tempo de serviço contados em dobro, e corrigida, para sempre, por qualquer reajuste ou vantagem, de qualquer natureza, concedidos aos ativos.

$\mathrm{Na}$ verdade, em nosso entendimento, o grande problema da Administração Pública brasileira é o seu reduzido nivel de institucionalização e de profissionalização. O equacionamento deste problema somente pode se dar pela continuidade do processo de criação de uma burocracia efetiva, processo que já foi várias vezes tentado e, quase sempre, abortado.

Agravando o problema, encontramos, hoje, na Administração Pública Federal e, em grande parte, na de outros niveis de Governo, uma distorção que se vincula à utilização dos cargos em comissão para provimento de funções técnicas e de apoio ou para complementação dos vencimentos de servidores. Tal procedimento, infelizmente, vem sendo regra na Administração Federal. A depressão da remuneração e a baixa qualificação dos servidores, bem como a pouca importância que vem sendo dada ao princípio do mérito e a despreocupação com o funcionamento eficiente e eficaz da Administração Pública têm conduzido a este caminho.

Citando DAlı.ArI, Adilson Abreu:

"[...] cabe, agora enfrentar a questão de fundo, qual seja, a dos 
limites à criação de cargos em comissão. É evidente que, se a administração puder criar todos os cargos com provimento em comissão, estará aniquilada a regra do concurso público. Da mesma forma, a simples criação de cargo em comissão, sem que isso se justifique, significa uma burla à regra do concurso público.

Márcio Cammorosano [in "Provimento de cargos públicos no Direito brasileiro, p. 95] abordou o assunto com rara felicidade, nestes termos: "Com efeito, verifica-se desde logo que a Constituição, ao admitir que o legislador ordinário crie cargos em comissão, de livre nomeação e exoneração, o que faz com que a finalidade de propiciar ao chefe do governo o seu real controle, mediante o concurso, para o exercício de certas funções, de pessoas de sua absoluta confiança, afinadas com as diretrizes politicas que devem pautar a atividade governamental. Não é, portanto, qualquer plexo unitário de competências que reclama seja confiado o seu exercício a esta ou aquela pessoa, a dedo escolhida, merecedora da absoluta confiança da autoridade superior, mas apenas àqueles que, dada a natureza das atribuições a serem exercidas pelos titulares, justificam exigir-se deles não apenas o dever elementar de lealdade às instituições constitucionais e administrativas a que servirem, comum a todos os funcionários, como também um comprometimento político, uma fidelidade às diretrizes estabelecidas pelos agentes políticos, uma lealdade pessoal à autoridade superior'.

É inconstitucional a lei que criar cargo em comissão para o exercício de funções técnicas, burocráticas ou operacionais, de natureza puramente profissional, fora dos niveis de direção, chefia e assessoramento superior". 8

Assim, não pode, em nenhuma hipótese, a Administração criar cargos em comissão que não sejam para o exercicio de funções de caráter político, com poder efetivo de decisão autônoma. Malgrado este fato, o que tem ocorrido é que, ao arrepio da norma moralizadora da Constituição de 1988, tem sido regra a criação de cargos em comissão para o exercício de funções absolutamente típicas de cargos efetivos. Tal procedimento ganha ares de suma gravidade quando observamos que, nos últimos anos, enquanto a remuneração dos cargos efetivos tem sido, sistematicamente, corrigida abaixo dos indices inflacionários, a dos cargos em comissão vem obtendo aumentos reais significativos.

Cabe desenvolver algumas observações sobre a questão do custo da Administração, sempre colocada como a principal variável de qualquer definição na área. Diga-se de passagem, inclusive, que esta realidade é sintomática de um fato que comprova o que vem sendo aqui exposto. A questão fazendária é quase sempre colocada como a fundamental em 
razão desta área ser a única a possuir, como regra, burocracias bem constituidas. Assim, no geral, o Estado brasileiro se mostra incapaz de formular políticas públicas, salvo na área fazendária. Trata-se de grave distorção, uma vez que ela leva a que a Administração Pública se torne um fím em si mesma, na medida ern que o único setor em condições de implementar a ação estatal é aquele que tem como função, tão-somente, assegurar meios para a atuação dos demais.

O custo da Administração Pública deve ser julgado considerando-se os resultados. É preciso considerar a relação custo-beneficio e não apenas o numerador da relação.

Certo que a Carta de 1988 criou despesas que cumpre corrigir. Dentre estas a questão previdenciária se destaca e é de correção urgente, para resgatar o sentido da existência de uma politica de seguro social.

Trata-se de questão que vem merecendo grande atenção nos últimos anos. As disposições constantes da Constituição de 1988, concedendo estabilidade aos servidores não admitidos por concurso público e estabelecendo a unificação do regime juridico, aumentaram sobremaneira a quantidade de servidores sujeitos ă aposentadoria estatutária, à qual, inclusive, foram acrescentados, pela própria Carta e por sua regulamentação, benefícios e vantagens não previstos nas Cartas anteriores, o que fez com que a renda do in tivo seja, sempre, maior do que a do ativo. Além disto, não cuidou a Carta e, pior, a legislação infraconstitucional, dos diversos entes federados de dar lógica atuarial ao sistema previdenciărio dos servidores públicos. Fsqueceu-se de que o benefício previdenciário deve ter, sempre, fundo contributivo.

Tal fato vem elevando significativamente a participação das despesas com inativos e pensionistas no total das despesas com pessoal, chegando mesmo a ameaçar as finanças públicas de alguns entes da federação. A própria União, onde o problema não tem a dimensão vivida especialmente por alguns municipios, vem despendendo, com inativos e pensionistas, cerca de $40 \%$ da totalidade de suas despesas com pessoal.

Assim, impõe-se equacionar a questão, sob o risco de dificultar a realização das reformas exigidas pela realidade social e, em alguns casos, mesmo de impedir a continuidade da prestação dos serviços públicos, na medida em que os Tesouros Nacional, Estaduais, Municipais e do Distrito Federal podem ser obrigados a restringir investimentos e a reduzir a manutenção da máquina pública para financiar os seus inativos.

De outra parte, é necessário atentar-se para a especificidade das atividades desempenhadas pelos servidores públicos. Tais funções, via de regra, exigem continuidade e permanência e têm a sua remuneração regulada mais pelas condições das finanças públicas do que pelo mercado.

Conceder aos servidores públicos condições de aposentadoria idênticas às da iniciativa privada pode ter efeito contrário ao pretendido. 
A redução das despesas com pessoal, embora obrigasse a Administração a concorrer com a iniciativa privada no recrutamento de profissionais, conduziria a uma rotatividade de mão-de-obra incompatível com o interesse público. Teríamos, dai, uma situação na qual os bons servidores acabariam abandonando o serviço público, enquanto os maus nunca se aposentariam. Tal fato é reconhecido internacionalmente, quando se constata que quase a totalidade dos paises do mundo adotam sistemas especiais de previdência para os seus servidores.

Uma terceira diretriz para o equacionamento do problema deve ser a garantia da própria razão de ser de um sistema previdenciário. É fundamental que esse sistema assegure a sobrevivência de seus beneficiários, após apresentarem algum tipo de incapacidade ou redução de sua capacidade laborativa, ao mesmo tempo que seja incorporada lógica atuarial ao sistema previdenciário dos servidores públicos.

A questão da estabilidade ou de seu fím, por sua vez, não pode, igualmente, ser equacionada numa perspectiva exclusiva de necessidade de redução de despesas públicas.

$O$ instituto da estabilidade deve resgatar a sua origem. Servidor público deve ser estável porque isto é importante para garantir a continuidade, a eficiência, a eficácia e a probidade da Administração Pública, não porque tal instituto seja um direito da categoria. A estabilidade no serviço público não pode ser entendida como um princípio que se esgote em si mesmo.

Neste sentido, o texto constitucional não traz grandes problemas, especialmente porque ele é corolário do principio da impessoalidade e do direito de defesa. Trata-se, em nosso entendimento, de regulamentá-lo bem. Cabe tipificar melhor as faltas que podem levar à demissão e impõe-se tornar o processo administrativo mais ágil e flexivel e menos oneroso.

Inicialmente, é fundamental simplificar, radicalmente, o processo de apuração e punição de faltas leves. Conforme Riciolın, Ivan Barbosa:

“Advirta-se desde jả que não é tarefa simples [...] a imposição de qualquer penalidade a servidor público.

Caso a Administração pretenda aplicar pena a seu servidor precisará, antes, acusá-lo de alguma infração. A Constituição Federal estabelece, no seu Art. $5^{\circ}$., LV, que 'aos litigantes, em processo judicial ou administrativo, e aos acusados em geral são assegurados o contraditório e ampla defesa, com os meios e recursos a ela inerentes'.

Se assim é, tão logo o poder público acuse o servidor de alguma infração, precisará, a partir deste momento, instaurar um regular procedimento contraditório, abrindo possibilidade de ampla defesa e de completa instrução procedimental, com todos os meios de prova 
de inocência do acusado sendo-lhe deferidos. Entre essas provas arrolam-se a oitiva de testemunhas, as perícias, os exames, as diligências, as averiguações, as acareações, bem como quaisquer outros meios admitidos juridicamente. Apenas após encerrada essa completa instrução, para a qual poderá o acusado até mesmo nomear advogado, apenas então, resultando sólida a conviç̧ão do caráter infracional da conduta do seu agente acusado, poderá a Administração impor-lhe a pena merecida. Jamais poderá ser aplicada ao servidor 'sequer a pena de advertência', muito menos as demais, de maior gravidade, se não esgotada inteiramente e a contento toda a fase procedimental que englobe a ampla defesa do acusado, no plano administrativo.

Caso a Administração não promova, em qualquer caso, este procedimento referido, restará líqüido e certo ao servidor acusado seu direito constitucional de proteger judicialmente sua garantia de ampla defesa, para a qual the socorre o mandado de segurança". 9

O que ocorre, então, é que a Administração dificilmente tem condições de mobilizar tantos recursos para a punição de faltas extremamente leves, o que acaba conduzindo à tolerância e omissão das chefias, num procedimento que, certamente, não atende ao interesse público, uma vez que premia o mau funcionário.

Quanto às faltas graves, também impõe-se retirar os excessos do processo administrativo disciplinar. Citando novamente o mestre Rigolin:

“Na L. 8.112 [Lei n. 8.112, de 1990] o processo administrativo disciplinar mereceu todo um título, o Titulo V, que contém os Arts. 143 a 182. Além de todo este título, desde o Art. 127 e até o 142, a L. 8.112 prescreve responsabilidades e penalidades ao servidor e, deste modo, apenas pelo vastíssimo teor dessa matéria, conforme tratada na lei, já se percebe a extraordinária importância que para o serviço público, o próprio servidor e a vida da Administração apresenta a questão disciplina e os expedientes que the são afetos.

Apesar de exaustivamente disciplinado na lei, o processo administrativo disciplinar raramente na prática é exercitado com a freqüência com que deveria e, quando o é, dificilmente obtém o resultado de justiça de desejar.[...]

[...] não foi desta vez, ainda, que a Lei 8.112 extirpou da legislação anterior a deficiência técnica, notória em questão de processo administrativo discíplinar, mantendo institutos repetitivos e abundantes, exatamente onde os procedimentos exigem concisão e objetividades máximas - sem embargo da garantia de ampla defesa". 10 
Não se trata, aqui, de retirar o direito de defesa, mas de evitar que o mau funcionário seja beneficiado com mecanismos procedimentais intermináveis, que fazem com que a punição de um servidor estável tenha que levar anos para ser aplicada, consumir dezenas ou até centenas de horas de trabalho de vários outros servidores e constituir autos que, muitas vezes, atingem vários quilogramas de peso, obrigando a Administração a despender esforços que seriam muito melhor canalizados na busca do atingimento de suas finalidades.

Entretanto, o fundamental nesta matéria é a decisão política de se procederem às punições e à adequada gerência. Apesar de algumas falhas, como acima descrito, existe legislação rigida para a punição do mau servidor e do incompetente que, na maior parte das vezes, tão-somente, não é aplicada.

A questão aqui está vinculada, também, à inexistência de uma burocracia orgânica. A ausência da idéia de continuidade no serviço público, bem como a falta de mecanismos institucionais de aferição de mérito para admissão e progressão, fazem com que o nível de exigência, pelas gerências, acerca da qualidade do serviço prestado, seja extremamente baixo.

O grande problema do desmesurado crescimento dos quadros funcionais de alguns entes governamentais é que ele não foi acompanhado da melhoria da qualidade do serviço público prestado à população. Em muitos municípios e mesmo em muitos Estados e na União, a máquina administrativa cresceu por motivos estranhos às necessidades da Administração Pública. Assim, esse crescimento não é produto da estabilidade, mas antes dos mecanismos não-burocráticos de organização da Administração. O fim da estabilidade, nestes casos, não terá como conseqüência a melhoria do serviço. Quando muito, ter-se-á uma violenta redução de quadros presidida pelos mesmos critérios que levaram ao seu crescimento. E, provavelmente, observaríamos, em seguida, um reacender do ciclo, jả que são mantidas as condições que permitem o seu florescimento.

Novamente, a solução do problema somente passa por uma mudança de postura com relação à administração da coisa pública, com a conseqüente melhoria dos sistemas gerenciais. Isto, inclusive, certamente contribuiria para a redução do custo da máquina administrativa. Tanto em termos relativos, na medida em que se reduziria drasticamente a relação custo-beneficio, quanto em termos absolutos, uma vez que a mera exigência de as pessoas executarem as atividades para as quais foram admitidas no serviço público certamente provocaria uma saída voluntária daqueles que integram os quadros apenas para a percepção dos vencimentos, possuindo, inclusive, outras atividades. É importante observar que este tipo de postura de desrespeito à coisa pública não tem relação com 
a estabilidade, uma vez que o quadro não era diverso antes de sua generosa extensão pelo Ato das Disposições Constitucionais Transitórias.

No que diz respeito à questão do regime jurídico único, cabe discuti-la com cuidado. É fundamental que ele não seja tomado como mito; nem como o responsável pelas mazelas da Administração Pública, nem como a solução mágica para os problemas de recursos humanos do serviço público. Nenhuma dessas posições encontra correspondência na realidade.

É muito comum, nos últimos tempos, a existência de ferozes criticas à obrigatoriedade constitucional de implantação do regime jurídico único para os servidores da administração direta, autárquica e fundacional, sob o argumento de que este teria provocado o "engessamento" geral da $\Lambda$ dministração Pública e retirado toda a sua flexibilidade, necessária em vista de sua diversidade. Efetivamente, o que buscam muitas dessas críticas é o retorno à situação anterior, de não institucionalização da relação entre o Estado e seus servidores, quando os dirigentes tinham total autonomia para admitir, fixar remuneração, promover, ascender e até dispensar. Trata-se de procedimento que, além de ferir os princípios basilares da Administração Pública, conduz, como conduziu no passado, ao grande crescimento da despesa pública. Além disso, é fundamental considerar que o regime estatutário tem caracteristicas mais adequadas para a relação entre o Estado e seus funcionários do que o contratual, de dificil compatibilidade com o princípio da legalidade e da reserva legal das matérias relativas a servidores públicos. É necessário, ainda, considerar a dificuldade e a inconveniência de o Estado estabelecer relações bilaterais com seus servidores.

É preciso atentar, aqui, se se pretende, de fato, combater a existência do regime estatutário, como conceito, ou se se ataca o principio quando o problema é o estatuto vigente. Não se pode pretender o fim do conceito constitucional pelos eventuais defeitos da sua regulamentação. Inclusive sem se verificarem as conseqüências que o fim da relação estatutária poderia trazer para as finanças públicas.

A demanda pela existência de regimes jurídicos diferenciados tem que ser analisada considerando que o problema que se coloca aqui é, antes, o da pouca definição sobre as áreas de atuação do poder público e da distribuição de encargos entre os niveis de Governo.

Talvez a inadequação do regime estatutário se deva ao fato de a União, os Estados ou os municípios estarem desenvolvendo atividades estranhas às suas competências. Trata-se de discutir o próprio pacto federativo e as funções do Estado.

As regras do concurso público não podem ser alteradas, sob o risco de repetir o retrocesso já vivido em 1946 e intensificado na década de 1970. Pelo contrário, é fundamental que sejam expurgadas todas as formas 
de provimento derivado. Trata-se da única alternativa para a constituição de uma burocracia orgânica, da instituição de um ethos do serviço público e de garantia da moralidade e da impessoalidade da gestão da coisa pública. E, antes de tudo, é exigência básica do direito de acesso de todos os cidadãos à função pública, de conformidade com a sua capacidade. Condena-se o concurso público como inadequado para a escolha de candidatos para tarefas simples ou para atividades de grande complexidade. O problema é a incapacidade de se organizarem concursos adequados.

Acusa-se o concurso, por exemplo, de impossibilitar a contratação de trabalhadores para funções braçais. Cabe perguntar, apenas, se não houver concurso, como será a seleção. Dificilmente poderá ser feita levando em conta o princípio da impessoalidade.

Igual questão pode ser levantada quanto à seleção para cargos de conteúdo atributivo complexo, sob risco de se retroagir a uma realidade que está sendo superada com grande dificuldade.

A simples supressão deste instituto ou a sua flexibilização traria conseqüências deletérias para a Administração Pública, uma vez que teria como resultado a paralisação do processo de institucionalização do serviço público que vem tomando corpo, lentamente e contra uma grande resistência, desde a edição da Carta de 1988.

\section{Considerações finais}

Assim, entendemos que a solução para o equacionamento dos graves problemas por que passa a Administração Pública brasileira somente poderá ocorrer se se caminhar no sentido da sua institucionalização, da constituição de uma burocracia efetiva, permanente. Trata-se de continuar na direção apontada pela Constituição de 1988 que, apesar de exageros que podem ser corrigidos - e que, na maior parte das vezes constam de suas disposições transitórias ou, mesmo, são de responsabilidade da legislação infra-constitucional, ao arrepio da própria Lei Maior - , representa o maior avanço já apresentado por um texto constitucional, indicando a direção da democratização e da moralização da gestão pública.

É fundamental que não tentemos alterar a Constituição, quando os problemas são de cunho infra-constitucional, ou mesmo, de gerenciamento e de decisão política. Não se pode repetir um equivoco da Constituinte de 1987/88, quando se acreditou que seriam dadas soluções imediatas a graves questões pela simples inclusão de dispositivos na Carta Magna.

Investir no modelo superado pela vigente Constituição é retrocesso na direção do fortalecimento da pseudoburocracia, que ainda comanda setores estratégicos da Administração Pública e resiste à perda do alcance de seu poder discricionário e ao seu enquadramento nos limites formais 
que a gestäo pública exige, como decorrência da legalidade e da impessoalidade, bem como mostra pouco respeito pelos mecanismos institucionais de mérito, uma vez que foi alçada às suas elevadas funções ao largo deles.

Não podemos desperdiçar, erraticamente, mais uma geração no processo de busca de uma Administração Pública eficiente e eficaz, capaz de formular e implementar políticas públicas, e que seja, igualmente, fruto da democracia e das conquistas da cidadania.

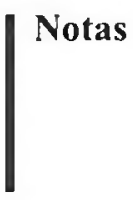

I SANTOS, Luiz Alberto dos. "O modelo brasilciro para a organização da alta administração". Revisu do Serviço Píblico, ano 46, vol. 119, n. 2/3, mai/dez, 1995, p. 77-94.

2 Por exemplo: Ata no. 56/90 Plenário Proc. no. TC 019.068/90-5: Ata n. 8/91 Plenário Proc. no. TC 575.400/89-7;

Ata n: 22/92 Plenário Proc. no. TC 006.658/89-0 - Decisão n: 236/92;

Ata n: 16/92 23. Câmara Proc. n. TC 034.080/91-0 - Decisão no 202/92 c

Proc. n? TC 250.521/91-1 - Decisão n'. 204/92;

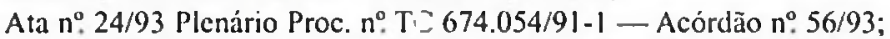

Ata no. 29/93 Plenário Proc. no. TC 024.653/92-6 - Decisão n: 283/93; c

Ata n. 30/93 Plenário Proc. no. TC 325.308/92-6 - Decisão n. 311/93).

${ }^{3}$ Mello, Celso Antonio Bandeira de. Curso de Direito Administrativo. São Paulo: Matheiros, 1993, p. 145.

${ }^{4}$ Rigolin, Ivan Barbosa. Comentários ao Regime Único dos Servidores Piblicos Civis. São Paulo: Saraiva, 1992, p. 364.

5 Ferreira, Wolgran Junqueira. Comentários à Constituição de 1988. São Paulo: Julex, 1989, p. 1236-37.

${ }^{6}$ Rigolin, Ivan Barbosa. Op. Cit., p. 65.

${ }^{7}$ Carneiro, João Geraldo Piquet. "As reformas da Administração Federal nos Governos Sarney e Collor". Brasilia: mimeo, 1993.

8 Dallari, Adilson Abreu. "Regime constitucional dos servidores públicos". Revistu dos Ti ibunais, São Paulo, 1992, p. 40-41.

${ }^{9}$ Rigolin, Ivan Barbosa. Op. Cit., p. 220-21.

10 idem, p. 66-67.

\section{Referências bibliográficas}

Carneiro, João Geraldo Piquet. "As reformas da Administração Federal nos Governos Sarncy c Collor". Brasilia: mimco, 1993.

Constituiçòes Estaduais. Brasilia, Senado Federal, 1992.

DALlaRI, Adilson Abreu. "Regine constitucional dos servidores públicos". Revista dos Tribunais, 2 ed. São Paulo, 1992. 
Ferreira, Wolgran Junqueira. Comentários à Constituição de 1988. São Paulo: Julex, 1989.

Mello, Celso Antonio Bandeira de. Curso de Direito Administrativo. São Paulo: MaIhciros, 4 ed., 1993.

Pareceres da Consultoria Geral da República. Brasilia, Imprensa Nacional, 1991, v. 101 e 102.

Rigolin, Ivan Barbosa. Comentários ao Regime Único dos Servidores Públicos Civis. São Paulo: Saraiva, 1992.

SANTOS, Luiz Alberto dos. "O modelo brasileiro para a organização da alta administração". Revisła do Serviço Priblico, ano 46, vol. 119, n. 2/3, mai-dez 1995, p. 77-94.

\section{Resumo \\ Resúmen \\ Abstract}

\section{Tentativas e perspectiva de formaçāo de uma burocracia pública no Brasil} Gilberto Guerzoni Filho

Análise da questão da formação da burocracia pública no Brasil, desde a criação do Conselho Federal do Serviço Público Civil em 1936 até as condições dadas pela Constituição Federal de 5 de outubro de 1988. Perspectivas e dificuldades de sua consolidação na situação atual. As experiências ocorridas no periodo: o Estado Novo, o processo de Redemocratização de 1946, o governo Kubitschek, o Movimento de $1964 \mathrm{c}$ as grandes reformas sob o Decreto-Lei no. 200, de 1967, a crise dos anos 80 , a Constituição de 1988 c a Administração Pública sob a Carta atual. Discussão dos temas $\mathrm{cm}$ debate no momento sobre a questão da Administração Pública: estabilidade, regime jurídico, concurso público, previdência.

\section{Tentativas y perspectiva de la formación de una burocracia pública en Brasil Gilberto Guerzoni Filho}

El texto hace el análisis de la formación de la burocracia pública en Brasil, desde la creación del Conscjo Federal del Servicio Público Civil en 1936 hasta las condiciones puestas por la Constituição Federal del 5 octubre de 1988. Explana, además, las perspectivas y dificuldades de la consolidación de esa burocracia en la actualidad, asi como las experiencias ocurridas en el periodo: el Estado Novo, el proceso de redemocratización de 1946, el Gobierno Kubitscheck, el Movimiento de 1964 y las grandes reformas bajo el Decreto-Ley II $^{\circ}$ 200, de 1967, la crisis de los años ochenta, la Constitución de 1988 y la Administración Pública en función de la Carta actual. Discute, también, temas emergentes sobre la cuestión de la Administración Pública: estabilidad, régimen juridico, concurso público y seguridad social.

\section{The building of bureaucracy in Brazil: models and perspective}

\section{Gilberto Guerzoni Filho}

The author analyses in a historical perspective the process of the formation of the public bureaucracy in Brazil, since the creation of the Federal Council for Public Service (Conselho Federal do Serviço Público) in 1936 until the approval of the Federal Constitution in 1988. He reviews important processes such as the Estado Novo, the democratisation process of 1946 , the Kubitscheck administration, the military regime of 1964, the economic crises of the 1980's and some of their outputs like the great reform of 1967 (decree-law $n^{\circ}$. 200), the Constitution of 1988 and the principles of administration there included. The author then discusses contemporary issues on the theme (civil servants stability, the regime jurídico único, entrance by public conquest, welfare) and evaluates the difficulties and perspectives of the consolidation of the present process of public administration formation in Brazil. 